\title{
Demonstration of a Fiber Powered Extender for PON Applications
}

\author{
Rivael Strobel Penze, Joao B. Rosolem, Ulysses R. Duarte, Getulio E. R. Paiva, and Renato Baldini Filho
}

\begin{abstract}
This work proposes a new approach to powering PON extenders using the fiber powering technique, in order to make them virtually passives. In our demonstration, we show the feasibility of this technique applied to an SOA based extender for XG-PON/G-PON shared network reaching a distance of $50 \mathrm{~km}$ with a split ratio of $1: 32$. Results regarding the BER measurements and extender optical performance are discussed. This approach eliminates the batteries in the remote sites improving the reliability and the security of the system.
\end{abstract}

Keywords- Optical access, fiber powering, optical fiber amplifiers, optical fiber communications.

\section{INTRODUÇÃO}

Current passive optical networks (PON), such as gigabit passive optical network (G-PON) or gigabit Ethernet passive optical network (GE-PON), are recognized as market leaders in optical access deployments. The natural evolution of these networks converges for 10 gigabit passive optical network (XG-PON or 10G-PON), but coexisting in the same infrastructure with G-PON or GE-PON legacy.

Extending the reach of a PON can provide several benefits such as covering wider areas and with large splitting, avoidance of the practice of installing remote optical line termination (OLT) and permission to the central office (CO) to consolidate which leads to a simplified network architecture, and a reduction in OPEX [1-2]. In order to maximize the XGPON/G-PON systems to longer reach and larger splitting ratio, semiconductor optical amplifiers (SOA) based on extenders were proposed [3-5]. As already stated the use of extendedreach PON can provide several benefits but telecom operators greatly value the passive nature of the access network enabled by the PON architecture. Therefore, much effort has been devoted to develop passive PON extenders. In this context two proposals have excelled: the erbium-doped fiber remote amplification [6-10] and the Raman amplification at central premises associated or not with SOAs [11-14]. The first proposal uses well-established technical and commercial characteristics of the erbium-doped fiber that is remotely pumped to promote the extension reach. Unfortunately this application concerns to the spectrum range of $\mathrm{C}$ band (1530$1565 \mathrm{~nm})$ or L band $(1570-1600 \mathrm{~nm})$ and therefore it isn't appropriate for application in full spectrum range of G-PON and XG-PON systems (1270-1360 nm, 1480-1500 nm and $1575-1580 \mathrm{~nm})$. The Raman amplification proposal is a very interesting technique to promote the passive long reach PON, however the technology for the Raman pumps for spectrum range of G-PON and XG-PON systems wavelength is not reliable and its manufacturability has not been fully proven yet. Furthermore, there are also safety issues regarding the handling of high optical power in a transmission fiber. A new approach to become passive the extenders is the fiber powering technique (FP) (or power over fiber). FP consists of transmitting optical energy by fiber for a distance and to transform it in electrical energy in a remote site by using a photovoltaic converter. This technique eliminates the batteries in the remote sites improving the reliability and the security of the system. Some research works on fiber powering techniques have been presented concerning PON applications. In [15] the constraints on optical powering in fiber-in-the-loop applications and issues such as safety and reliability were investigated. Finally, in [18] Raman pump was applied to the remaining optical power at the receiver to convert it to electrical power in the optical network terminal (ONT). This paper presents a new approach to powering PON extenders using the fiber powering in order to make them virtually passive. The limits and the perspectives for this approach are discussed. The performance of a fiber powered SOAs based extender is also demonstrated with an XG-PON/G-PON system set-up using a 1:32 splitter and $50 \mathrm{~km}$ reach. The conventional method to power the extender is presented for the sake of comparison with the proposed fiber powering technique.

\section{POWERING THE PON EXTENDERS}

\section{A. Powering the extender by the conventional method}

In the conventional method, PON extenders are treated as remote terminals, such as, media gateways deployed in the last mile of the fiber-to-the-home (FTTH) networks. According to Fig. 1(a) (option A), the extender can be installed in an environmental controlled enclosure system placed in curbside ground mount, pole mount or in buried junction boxes. These enclosures include equipment rack mount place for the electro-optic devices, fiber management, power supply, standby batteries, sometimes solar panels, alternate current (AC) service entrance, AC power distribution, and surge protection constituting an uninterruptible power supply (UPS). Both ground and pole mount enclosure systems are required, with ground mount enclosures representing an increase of $25 \%$ in cost due to the higher degree of planning, permitting, trenching, disruptive groundwork, and the concrete pad needed for mounting that enclosure. The enclosure is designed and qualified as a system with convection cooling airflow, component placement and ventilation and must avoid the entrance of water, snow, and dust. Passive thermal management must address the total thermal load of the optics and power supply under full load conditions and variation in battery temperatures. The temperature variation between batteries is critical and should be kept below $5^{\circ} \mathrm{C}$ to assure proper temperature charge compensation. Other considerations include power supply and status monitoring, regulatory compliance, grounding, surge protection and the materials 
selected should support a long service life.

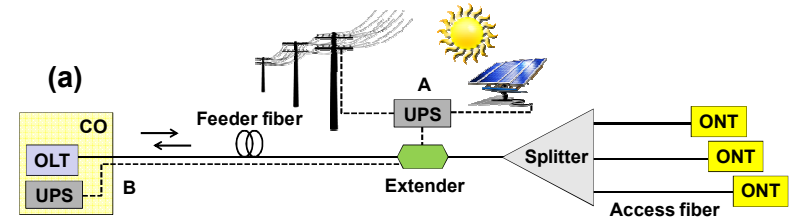

(b)

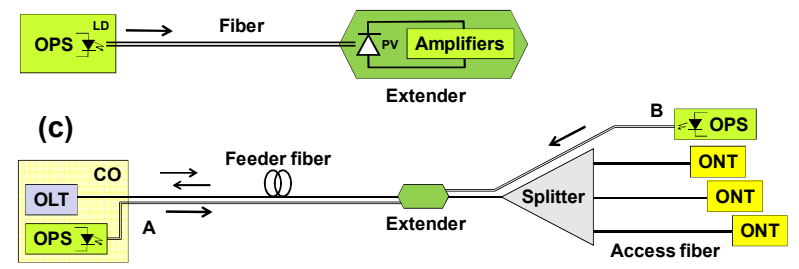

Fig. 1 - Powering techniques to uses with PON Extender, (a) standard wiring and local electrically powering, (b) fiber powering technique diagram and (c) extender powered by $\mathrm{CO}$ or by the remote note.

Fig. 1(a) option B shows another way to power the remote nodes using the electrical method. It uses the existing copper wires to extend the $\mathrm{CO}$ power, where the OLT is installed, to the PON extender. This scheme is commonly referred as Line Power.

This approach has been studied to powering optical network terminals (ONT). Typically, a reliable $-48 \mathrm{~V}_{\mathrm{dc}}$ power plant and battery backup system serve as the ultimate source for the line power. The line power system converts in the $\mathrm{CO}$ the $-48 \mathrm{~V}_{\mathrm{dc}}$ to $\pm 190 \mathrm{~V}_{\mathrm{dc}}$ through the deployment of dc-de converters, named converters. The $\pm 190 \mathrm{~V}$ is carried over copper pairs to the destination, where this voltage is converted back to $-48 \mathrm{~V}_{\mathrm{dc}}$ or $-12 \mathrm{~V}_{\mathrm{dc}}$, which is named down converter.

The type of cable, the distance from the $\mathrm{CO}$, and power consumption are primary considerations in designing the line powered, once the voltage drops in the copper pairs are the main problem with this method. There may be safety concerns as well, due to the use of high voltage and the occurrence of lighting.

\section{B. Powering the extender by fiber}

Fig. 1(b) shows a simple configuration of a system to be applied to powering a PON extender. This system consists of the following components: an optical power source (OPS) with a laser driver circuit, a high power laser which converts the electrical power to optical power, the fiber that transports the optical power, an extender with a photovoltaic cell (PV), which converts the optical power back to electrical power, and the optical amplifiers to amplify downstream an upstream signals in the PON. Fig. 1(b) shows just one single way to powering, however it is possible to use in the OPS extra laser diodes (LDs) and fibers to increase the transmitted power. It is also possible to connect other PVs to increase the converted power in the extender. Fig. 1(c) illustrates two possibilities to powering the extender, from the $\mathrm{CO}$ (option $\mathrm{A}$ ) or from a remote node (option B). Option A is very similar to that one used in erbium-doped remote amplification, or by copper pairs showed Fig. 1(a). In option B, the OPS is installed in a point of presence of telecom companies, such as, shopping centers, gated communities, rent rooms, etc.. The amount of power that the fiber powering system can deliver is determined in great extent by its components: laser, fiber and photovoltaic cell.
The following parameters can be used to evaluate the delivered power to an extender $\left(P_{\text {Extender }}\right)$ : the supply optical power on the PV $\left(P_{S u p}\right)$; the maximum transmitted optical power without causing damages in the optical fiber $\left(P_{\text {MaxFiber }}\right)$; the power of the laser diode $\left(P_{L D}\right)$; the total loss on the fiber $\left(\alpha_{\text {Fiber }}\right)$; the link distance $(d)$ in $\mathrm{km}$ and the efficiency of the PV $\left(\eta_{P V}\right)$. The power delivered to an extender can be expressed by:

where

$$
P_{\text {Extender }}=P_{\text {Sup }} . \alpha_{\text {Fiber }} . \eta_{P V}[\mathrm{~W}],
$$

$$
\alpha_{\text {Fiber }}=10^{-d \cdot \alpha_{d B}},
$$

and $\alpha_{d B}$ is the fiber attenuation in $\mathrm{dB} / \mathrm{km}$. Notice that:

$$
P_{L D} \leq P_{\text {MaxFiber. }} \text {. }
$$

Fig. 2 illustrates the simulation of $P_{\text {Extender }}$ values as a function of the link distance $d$. For single-mode fiber with core of $9 \mu \mathrm{m}$ in $1480 \mathrm{~nm}$ applications the parameters used are $P_{L D}$ $=0.5 \mathrm{~W}, P_{\text {MaxFiber }}=1.0 \mathrm{~W}, \alpha_{d B}=0.25 \mathrm{~dB} / \mathrm{km}$ and $\eta_{P V}=0.2$. For multimode fibers with core of $62.5,105$ and $200 \mu \mathrm{m}$ in $808 \mathrm{~nm}$, the parameters used are $P_{L D}=2,4$ and $7 \mathrm{~W}, P_{\text {MaxFiber }}$ $=2,4,8 \mathrm{~W}$, respectively, $\alpha_{d B}=3.0 \mathrm{~dB} / \mathrm{km}$ and $\eta_{P V}=0.35$.

Although the fiber used in PONs is generally single-mode, multimode fibers of larger diameter are also suitable for optical power transmission. Multimode fibers can be utilized along with a single mode cable communications at small additional cost.

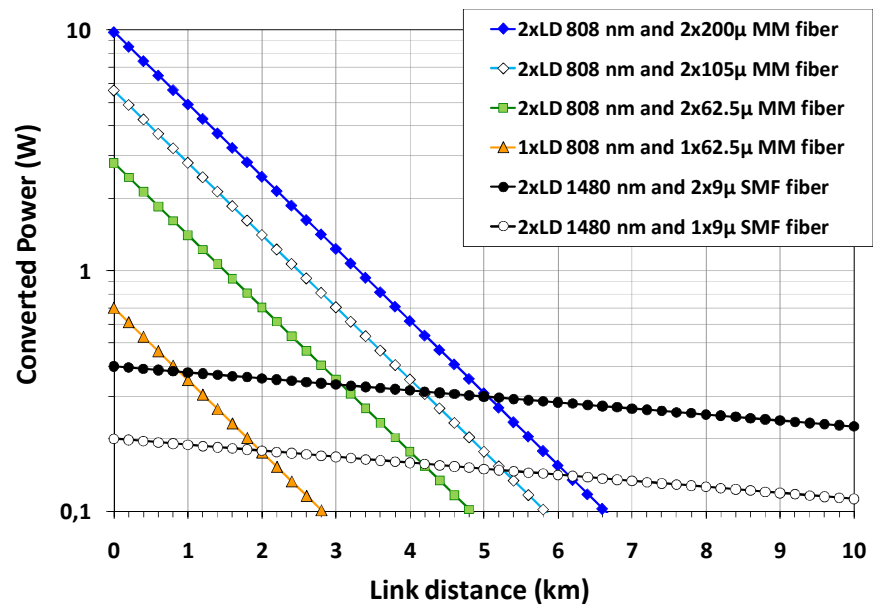

Fig. 2 - Simulation of the power converted in the Extender as a function of the link distance $d$.

A crucial parameter of the extender is power consumption. The power source needs to have protection against failures of the primary power source, typically using batteries as a backup. Therefore, power consumption should be reduced as much as possible. Moreover, the reach extender must support full management of its configuration, performance monitoring and fault reporting. Thus, for the mid-span extender, a simple way to overcome these requirements is to supply the extender equipment with the functions of an ONT.

However, such functions require more electronic circuits that increase power consumption. Typical power consumption in the extenders ranges from 5 to $8 \mathrm{~W}$. From Fig. 2 it is possible to conclude that the converted power will be available only for short distances from the OPS. This eliminates the approach presented in Fig. 1(c) (Option A) because the typical distances used for extended applications is above $20 \mathrm{~km}$ from the CO. Option B in Fig. 1(c) seems to be a reasonable choice for extenders that use low power-consumption optoelectronic 
devices [16]. The next section presents a new approach for an extender configuration using SOAs with low power consumption and powered by the fiber.

\section{FIBER POWERED XG-PON/G-PON EXTENDER}

The proposed fiber powered PON extender is shown in Fig. 3. The proposed extender circuit provides gain for XG-PON and G-PON applications using minimum power consumption. In the extender circuit the two commercial SOAs (for $1310 \mathrm{~nm}$ and $1550 \mathrm{~nm}$ ) and the cooler devices packaged in butterfly capsules are electrically connected in cascade. The SOAs have similar electrical characteristics.



Fig. 3 - The proposed fiber powered extender.

This cascade circuit is electrically powered by just one single PV. Two 1310/1550 nm wavelength division multiplexers (WDM) are used at the input and output of the extender to couple light in SOAs to amplify simultaneously both XG-PON/G-PON downstream signals in the $1550 \mathrm{~nm}$ SOA. The upstream signals are amplified in the $1310 \mathrm{~nm}$ amplifier.

This proposed circuit allows the power consumption to be minimized by the extender. The current $I$ is supplied by PV and feeds the coolers of both SOAs. It is possible to monitor and control the extender using the technique described in [17].

The circuit showed in Fig. 3 is electrically characterized. Fig. 4 shows the voltage $V$ and current $I$ generated by the PV cell as function of the supply optical power $P_{\text {Sup }}$ on PV provided by one $830 \mathrm{~nm}$ laser coupled in a $62.5 / 125 \mu \mathrm{m}$ fiber. The maximum output power of the laser is $2 \mathrm{~W}$.

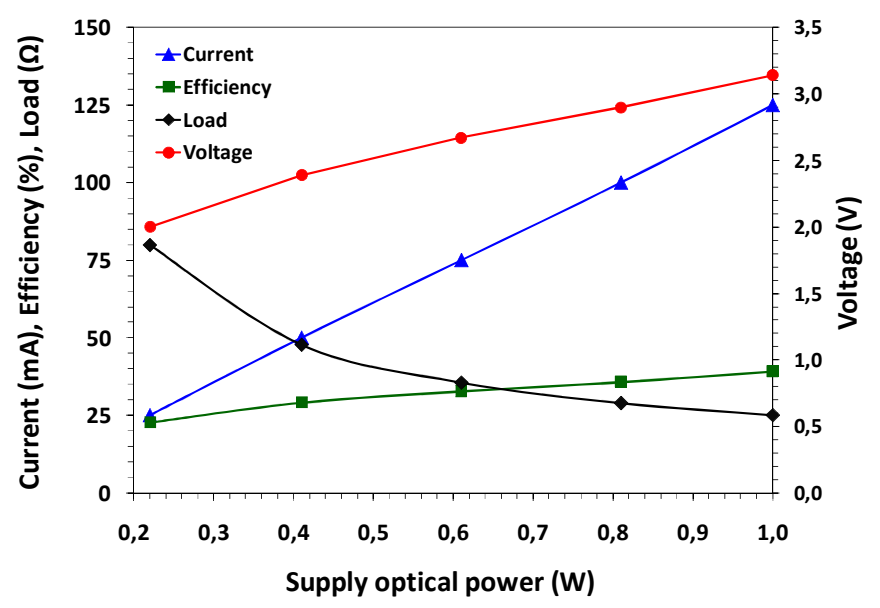

Fig. 4 - The electrical characterization of the extender.

Moreover, Fig. 4 shows PV cell parameters like efficiency
$\eta_{P V}$ in $\%$ and the associated load $L$ of the circuit. The PV cell efficiency and the associated load are given by:

$$
\begin{aligned}
& \eta_{P V}=\frac{100 \cdot V \cdot I}{P_{\text {Sup }}} \% \\
& L=V / I
\end{aligned}
$$

When the incident power in the PV cell is $1 \mathrm{~W}$ which corresponds a link distance of $1 \mathrm{~km}$, the associated parameters are: $V=3.14 \mathrm{~V}, I=125 \mathrm{~mA}, \eta_{P V}=39.25 \%$ and load $L=25.12 \Omega$.

\section{PROOF-OF-CONCEPT OF FIBER POWERED XG-PON AND G-PON EXTENDER}

\section{A. Virtually extender optical gain characteristics}

In order to investigate the feasibility of the proposed extended XG-PON/G-PON network, a set of proof-of-concept measurements employing the fiber powered extender were carried out (see Fig. 3) as a bidirectional in-line amplifier at the remote node (Fig. 1c, option B). The extender was characterized (Fig. 5) in terms of gain in the operational bands of XG-PON and G-PON systems versus the supply optical power for some levels of input power $\left(P_{i n}\right)$. The results presented in Fig. 5 were obtained from the experimental setup shown in Fig. 6. The typical values of the downstream and upstream input power $\left(P_{i n}\right)$ were adjusted in the extender input and the supply optical power $\left(P_{S u p}\right)$ in the PV was changed remotely. These results show the gains for each wavelength in different values of $P_{\text {sup }}$. Fig. 5 shows the extender gain for (a) $P_{\text {in }}=-12 \mathrm{dBm}$, (b) $P_{\text {in }}=-15 \mathrm{dBm}$, (c) $P_{\text {in }}=-18 \mathrm{dBm}$ and (d) $P_{\text {in }}=-21 \mathrm{dBm}$.

\section{B. $\quad$ System performance evaluation}

Fig. 6 depicts the test-bed employed for proof-of-concept measurements. The aim is to analyze the maximum available optical power budget provided by the extender in order to indentify the upper-reach limit. A $50 \mathrm{~km}$ single mode bidirectional feeder optical fiber connected the OLT to the remote node, where the virtually passive extender is placed for both upstream and downstream in-line amplification. A set of small form pluggable (SFP) transceivers were used for G-PON transmission and for the XG-PON upstream channel.

On the other hand, a 10G Small Form Pluggable (XFP) was required to generate the XG-PON downstream signal. Due to unavailability of transmitters centered at XG-PON grid, the following wavelength plan were chosen for this analysis: 1566 $\mathrm{nm}$ (XG-PON downstream); $1490 \mathrm{~nm}$ (G-PON downstream); $1290 \mathrm{~nm}$ (XG-PON upstream); and $1310 \mathrm{~nm}$ (G-PON upstream). Both G-PON and XG-PON signals were modulated using pseudo-random bit sequences of length $2^{23}-1$ and $2^{31}-1$, respectively. The transmitters output power levels were set at ONT and OLT transmitters, i.e., $1290 \mathrm{~nm}, 1310 \mathrm{~nm}, 1490 \mathrm{~nm}$, $1566 \mathrm{~nm}$, to $2 \mathrm{dBm}, 2 \mathrm{dBm}, 2 \mathrm{dBm}$ and $0.5 \mathrm{dBm}$, respectively.

In the OLT site, the G-PON and XG-PON downstream signals were combined using optical filters (see OLT inset on Fig. 6) and were sent over the $50 \mathrm{~km}$ single-mode fiber to the remote node for in-line amplification. The downstream signals were guided to the ONTs after amplification by the $1550 \mathrm{~nm}$ SOA passing through a power splitter in a 1:32 ratio. A set of optical filters (see ONT inset on Fig. 6) diverts the XG$\mathrm{PON} / \mathrm{G}-\mathrm{PON}$ signals to each downstream receiver (XFP/SFP). 

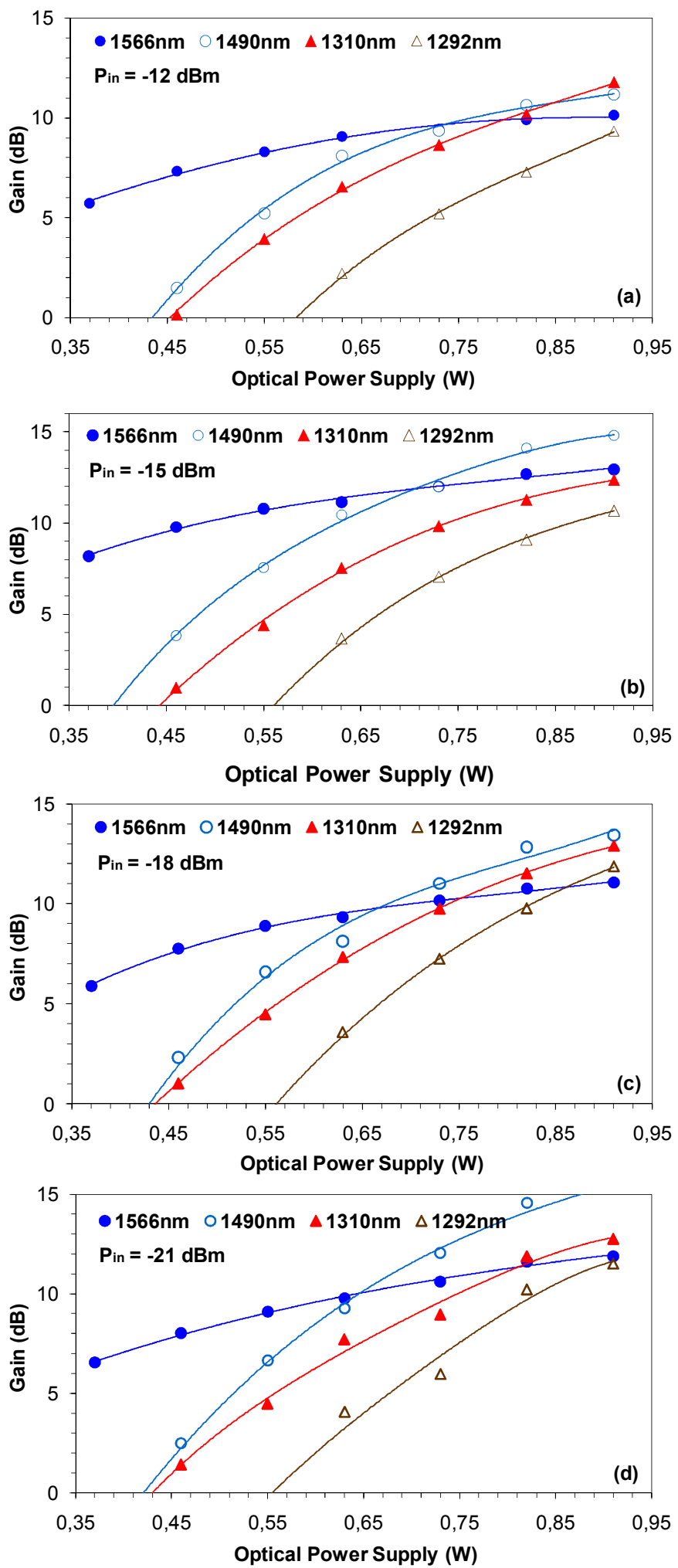

Fig. 5 - G-PON \& XG-PON signal gain as function of the $\mathrm{P}_{\text {Sup }}$, (a) Pin $=$ $12 \mathrm{dBm}$, (b) Pin $=-15 \mathrm{dBm}$, (c) Pin $=-18 \mathrm{dBm}$ and (d) Pin $=-21 \mathrm{~dB}$

For upstream transmission, the G-PON and XG-PON signals were combined by the optical filters set at ONT side (see ONT inset on Fig. 6) and transmitted to the PON network by an optical splitter. They were amplified at remote node by a $1300 \mathrm{~nm}$ SOA. Finally, the upstream output signals from virtually passive extender were sent over the $50 \mathrm{~km}$ singlemode fiber and demultiplexed for detection at OLT receivers (XG-PON and G-PON). In the optical fiber powering path, a $62.5 / 125 \mu \mathrm{m}$ multimode fiber with length of $1 \mathrm{~km}$ was used to emulate an optical link between the OPS (located close to a user termination) and the remote node, by passing the optical splitter. Both wavelength and launch power of the pump laser were set to $830 \mathrm{~nm}$ and $2 \mathrm{~W}$, respectively.

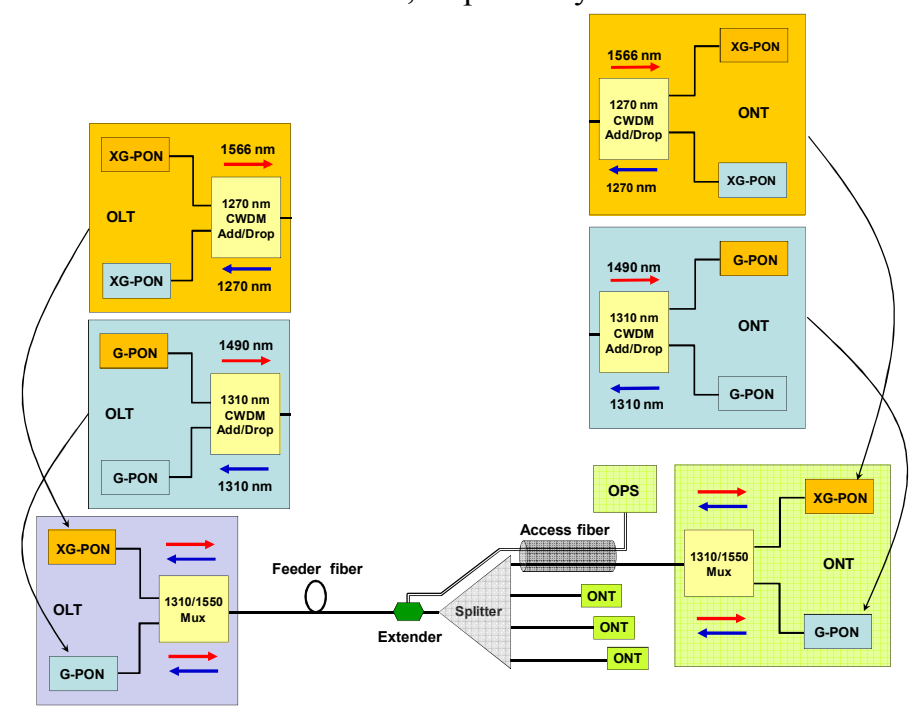

Fig. 6 - Setup proposed for systemic evaluation.

To estimate the transmission system performance we measured the bit error rate $(B E R)$ at the receivers. Although burst mode transmission was not used for the upstream signals analysis there is no impact in the SOA performance due to the transient effects [3] - [7]. The performance evaluation was conducted in terms of $P_{S u p}$ variation. $P_{\text {Sup }}$ was adjusted initially in a value that set the $B E R$ at $10^{-12}$ and then it was progressively reduced while the BER and the input optical power in the receivers in ONT and OLT for each wavelength were monitored. Fig. 7(a) and (b) shows the performance evaluation for XG-PON in upstream and downstream direction, respectively, and Fig. 7(c) and (d) shows the performance evaluation for G-PON in upstream and downstream direction. Notice that from Fig. 7(a) to (d) there is a tolerance around $10 \%$ in the major value of $P_{\text {Sup }}$ (around 0.9 $\mathrm{W})$ in which the $B E R$ is lower than $10^{-10}$ in the receivers (except for upstream XG-PON) which is acceptable for XGPON and G-PON systems.

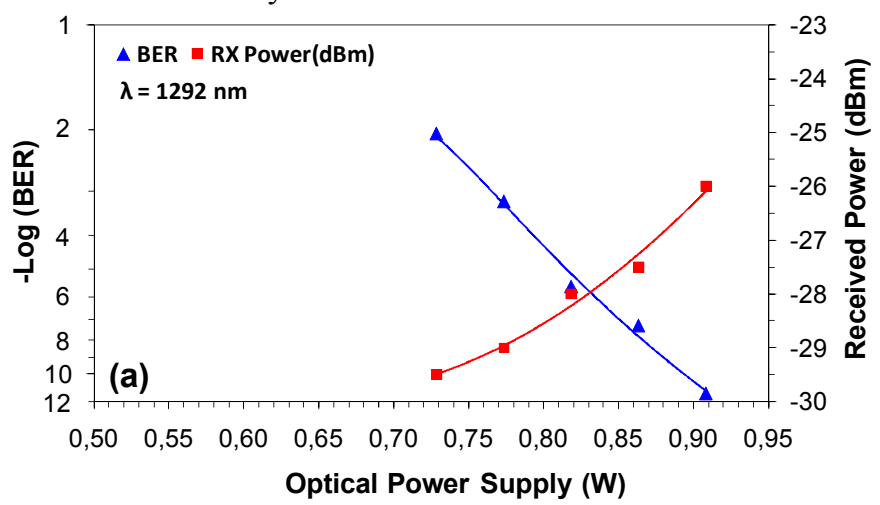





Fig. 7 - Performance evaluation of the proposed system for (a) XG-PON upstream, (b) XG-PON downstream, (c) G-PON upstream and (d) G-PON downstream.

\section{CONCLUSION}

This work has described a new approach to powering PON extenders using the fiber powering technique, in a way to make them virtually passives. The conventional method to power the extensors has been described to compare with the presented fiber powering technique. The limits and the perspectives for this approach have also been discussed. The performance of fiber powered SOAs based extender has been presented with a XG-PON/G-PON system set-up using a 1:32 splitter and $50 \mathrm{~km}$ reach. The proposed technique can improve the reliability and the confidence of the PON systems by eliminating the batteries in remote sides.

\section{ACKNOWLEDGEMENTS}

This work was supported by the Funttel/Finep Brazil, under GIGA Project.

\section{REFERENCES}

Rivael Strobel Penze, Joao Batista Rosolem, Ulysses R. Duarte, Getulio E. R. Paiva, Diretoria de Redes Convergentes Fundação CPqD, Campinas-SP, Brasil, emails rpenze, rosolem, uduarte e gpaiva@cpqd.com.br.

Renato Baldini Filho, DECOM, Unicamp, Campinas-SP, Brasil, email baldini@decom.fee.unicamp.br
[1] P. lannone, and K. Reichmann, "Strategic and Tactical Uses for Extended PON," in Opt. Fib. Conf./Nat. Fib. Opt. Eng. Conf. Invited Talk Presentation, San Diego, United States, Feb. 2008.

[2] R. P. Davey, D. B. Grossman, M. Rasztovits-Wiech, D. B. Payne, D Nesset, A. E. Kelly, A. Rafel, S. Appathurai, and S.-H. Yang, "LongReach Passive Optical Networks (Invited Tutorial)," J. Lightw. Technol., vol. 27, no. 3, pp. 273-291, Feb. 2009.

[3] F. Saliou, P. Chanclou, N. Genay, J. A. Lazaro, F. Bonada, A. Othmani, and Y. Zhou, "Single SOA to Extend Simultaneously the Optical Budget of Coexisting G-PON and 10G-PON," Proc. Europ. Conf. Opt. Comm. 2010, Torino, Italy, Sept. 2010, paper Tu.5.B.5.

[4] M. Oishi, T. Tsuritani, and K. Nishimura, "Extended-Reach 10G/1GEPON over $80 \mathrm{~km}$ and 1024 Split with Optical Amplifier-Based Hybrid Repeater," in Proc. Opt. Fib Comm./Nat. Fib. Opt. Eng. Conf. 2012, Los Angeles, United States, Mar. 2012, paper NTu1J.1.

[5] B. Le Guyader, F. Saliou, L. Guillo, M. Le Roux, B. Charbonnier, P. Chanclou, and J. Pascal, "Dual Reach Extender based on Optical Amplification for G-PON and symmetrical 10G-PON systems," in Proc. Opt. Fib Comm./Nat. Fib. Opt. Eng. Conf. 2012, Los Angeles, United States, Mar. 2012, paper NTu1J.2.

[6] J. Prat, and D. Pla, "Remote amplification in high-density passive optical networks," in Proc. Int. Conf. Transparent Opt. Networks 2005, Barcelona, Spain, vol. 2, pp. 409-412, Jul. 2005.

[7] J. Bauwelinck, B. Schrenk, F. Bonada, B. Baekelandt, J. A. Lazaro, P. Chanclou, J. Prat, X.Z. Qiu, "Full-Duplex $10 \mathrm{~Gb} / \mathrm{s}$ Transmission in Ultra-Dense PONs With Tree Splits $>1: 1 \mathrm{k}$ and Noise-Powered Extender Box", in Proc. Europ. Conf. Opt. Comm. 2010, Torino, Italy, Sept. 2010, paper Tu.5.B.4.

[8] B. Schrenk, F. B. Bo, J. Bauwelinck, J. Prat, and J. A. Lazaro, "Energyefficient optical access networks supported by a noise-powered extender box," IEEE J. Sel. Topics Quantum Electron., vol. 17, no. 2, pp. 480488, Mar.-Apr. 2011.

[9] B. Schrenk, J. Bauwelinck, F. B. Bo, J. A. Lazaro, X.-Z. Qiu, P. Chanclou, and J. Prat, "High Customer Density PON With Passive Amplification Through Distributed Pump for $>1: 1000$ Tree Split," in J. Lightw. Technol., vol. 29, no. 13, pp. 1951-1957, Jul. 2011.

[10] B. Schrenk, J. A. Lazaro, D. Klonidis, F.Bonada, F. Saliou, V. Polo, E. Lopez, Q. T, Le, P. Chanclou, L. Costa, A. Teixeira, S. Chatzi, I. Tomkos, G. M. T. Beleffi, D. Leino, R. Soila, S. Spirou, G. de Valicourt, R. Brenot, C. Kazmierski, and J. Prat, "Demonstration of a Remotely Dual-Pumped Long-Reach PON for Flexible Deployment," J. Lightw. Technol., vol. 30, no. 7, pp. 953-961, Apr.1 2012.

[11] K. L. Lee, J. L. Riding, A. V. Tran, and R. S. Tucker, "Extended-Reach Gigabit Passive Optical Network for Rural Areas using Distributed Raman," in Proc. OptoElectron. Comm. Conf. 2009, Hong Kong, China, Jul. 2009.

[12] D. Nesset, K. Farrow, P. Wright, and D. Menashe, "Raman Amplifier Module for G-PON Reach Extension," in Proc. Opt. Fib Comm./Nat. Fib. Opt. Eng. Conf. 2012, Los Angeles, United States, Mar. 2012, paper NTu1J.3.

[13] B. Zhu, "Entirely passive coexisting 10G-PON and G-PON compatible reach extender using Raman amplification," Opt. Exp., vol. 20, no. 3, pp. 2290-2296, Jan. 2012.

[14] L. Leng, and T. Le, "A Raman amplified G-PON reach extension system using parameters of a deployed fiber," Opt. Exp., vol. 20, no.24, pp. 26473-26479, Nov. 2012.

[15] T. C. Banwell, R. C. Estes, L. A. Reith, P. W. Shumate Jr., E. M. Vogel, "Powering the fiber loop optically-a cost analysis," J. Lightw. Technol., vol. 11, no. 3, pp. 481-494, Mar. 1993.

[16] J. B. Rosolem, G. E. R. de Paiva, and U. R. Duarte, "R-SOA Based Extender for XG-PON/G-PON Applications," in Proc. Opt. Fib Comm./Nat. Fib. Opt. Eng. Conf., Los Angeles, United States, paper OM3I.3.

[17] J. B. Rosolem, and C. Floridia, "Power control and temperature sensing for fiber-powered active sensors," Appl. Opt., vol. 47, no. 33, pp. 62076211, Nov. 2008.

[18] P. S. Andre, M. J. N. Lima, N. Fernandes, M. Granada, J. Cang, R. Lan, and X. Xiang-Jun, "Power over fiber in Raman amplified optical networks," in Proc. Int. Conf. Telecomm. 2011, Graz, Austria, pp.311314, Jun. 2011 